\title{
Aging and Gender Health Gap: A Multilevel Analysis for 17 European Countries
}

\author{
Patricia Gómez-Costilla ${ }^{1}$ - Carmen García-Prieto ${ }^{2} \cdot$ Noelia Somarriba-Arechavala $^{3}$
}

Accepted: 15 December 2020 / Published online: 4 January 2021

(c) The Author(s) 2021

\begin{abstract}
The European population is aging and their declining capacity makes older Europeans more dependent on the availability of care. Male and female health needs at older ages are different, yet there are contradictory results on the study of gender inequalities in health among the older European population. The aim of this article is twofold: first, we study whether there is a general gender health gap at older ages across Europe. Secondly, we analyze the existence of an increasing or decreasing universal association between the gender health gap and age among the older European population or whether, by contrast, this depends on the type of welfare state. To achieve these goals, we use data from the Survey on Health, Ageing and Retirement in Europe (SHARE) for respondents aged 50 and over in 2015, and we carry out several multilevel random intercept logistic regressions for European countries. Our results show that when we split European countries into groups according to the type of welfare state, we only find a significant gender health gap in older people in Southern and Social Democratic countries. Some differences have been found in the links between the gender health gap and age among European countries. Old women report worse health than men at all ages in Southern countries while in Social Democratic states it is only true for women aged 80 and over. In Bismarckian states there are barely any gender differences, while the gender health gap has no clearly defined bias. Between the ages of 60 and 79, men from Eastern European countries report poorer health, while after 80 it is women who report poorer health. In general, we found the widest gender inequalities in health for the oldest population group, especially in Southern and Eastern European countries.
\end{abstract}

Keywords Gender · Inequalities · Health · Aging · Welfare state · Multilevel · Europe

Patricia Gómez-Costilla

patricia.gomez.costilla@uva.es

1 Department of Economic Analysis, Facultad de Ciencias Sociales, Jurídicas y de la Comunicación, University of Valladolid, Campus María Zambrano, Plaza de la Universidad 1, 40005 Segovia, Spain

2 Department of Economic Analysis, University of Valladolid, Valladolid, Spain

3 Department of Applied Economics, University of Valladolid, Segovia, Spain 


\section{Background}

Health in the latter stages of life is a matter of great interest since older people are a particularly vulnerable population group. They suffer from high rates of dependency and chronic diseases, added to which their income tends to decrease as they get older and leave the job market. In doing so, they become highly dependent on the pension system and the state welfare provision. These characteristics make older women one of the most vulnerable groups in our societies, since it is well known that in most European countries, women's life expectancy is usually higher than men's. Yet as regards morbidity, it has frequently been found that women's perception of their own health is poorer, and that they usually refer more limiting long-term illnesses, which has been called the health paradox of women (Macintyre, Hunt and Sweeting 1996; Arber and Cooper 1999). Moreover, women begin to suffer from functional limitations earlier than men (Serrano-Alarcón and Perelman 2017), and are at greater risk of either widowhood or having to take care of a dependent partner (Carmel 2019). Elderly women are also vulnerable to a pension system that in most cases is male-centered (Högberg et al. 2017). Hence, it is not surprising to think that gender may be shaping the health inequalities observed among the elderly in Europe.

There is strong evidence supporting the influence of individuals' socioeconomic position, particularly income and educational inequalities on their own perception of their health (Mackenbach et al. 1997; Kunst et al. 2005; Hu et al. 2016; Adeline and Delattre 2017). Since the mid-twentieth century, public policies have been implemented to improve men's and women's health. The provision of universal health care services or the adoption of redistributive and equalitarian policies (among others) have been focused on the reduction of health inequalities in European countries, although there is no conclusive evidence of success (Mackenbach 2012; Maskileyson 2014) and important health inequalities continue to exist even within countries with high income and extensive welfare provision systems (Brennenstuhl, Quesnel-Vallée and McDonough 2012). Indeed, there is a large body of research on welfare regimes and their links to the reduction of health inequalities (Mackenbach et al. 2008). In an extensive review, Bergqvist, Yngwe and Lundberg (2013) highlighted how the use of different measures of health across studies leads to diverse and sometimes contradictory conclusions about where health inequalities are smaller.

In previous research, the usual socioeconomic gradient in health observed among the middle-aged population was also found at older ages (Dalstra et al. 2006). Indeed, some studies have reported the existence of socioeconomic inequalities in health among older European men and women even for those aged over 80, although a decreasing age-pattern has been observed (Beckett 2000; Huisman, Kunst and Mackenbach 2003). This tendency is referred to as the "age-as a leveler" hypothesis, and it has been explained mostly due to the mortality selection, since individuals with a lower socio-economic status experience higher mortality rates, thus reducing health inequalities among the survivor population. In contrast, in accordance with the cumulative disadvantage hypothesis, which proposes an increase in health inequalities over the life cycle, Bambra, Netuveli and Eikemo (2010) found that socioeconomic inequalities in health among the European elderly tended to increase with age, mainly in Southern European countries, where the magnitude of health inequalities was higher than in other welfare regimes.

Some explanations can justify the above-mentioned controversy. On the one hand, the use of different measures of socioeconomic position such as education, income, occupational class or wealth can lead to different results when studying the age trajectory of health inequalities, and using various socioeconomic position measures is recommended in order 
to gain a global perspective (Acciai 2018). Moreover, the use of different health indicators (self-rated health, number of chronic diseases, physical limitations...) is also a source of discrepancy in the conclusions (Leopold and Engelhartdt 2013). On the other hand, healthrelated behaviors can shape the relation between age and health inequalities, and the control for these factors may explain some of the contradictory results in the literature, such as the large health inequalities found in Nordic countries by some studies (Avendano, Jürges and Mackenbach 2009; Thorslund and Lundberg 1994).

Less attention has been paid to studying gender health inequalities among the elderly, and older people are very often included in wider analyses that study gender inequalities among the adult population as a whole (Bambra et al. 2009; Lahelma et al. 2002). The existence of gender differences in education, labor market participation and occupational class in our societies thus generates the well-known gender health gap, given the abovementioned relation between socioeconomic position and health (Macintyre, Hunt and Sweeting 1996; Pinillos-Franco and García-Prieto 2017). Nevertheless, in later life, it is not clear whether socio-economic position is more closely linked to health in older men or women, with contradictory results having been reported by different studies (Uccheddu et al. 2019). Some research points to gender differences in morbidity patterns at older ages, with higher female rates of chronic diseases and a greater prevalence of mental and depressive symptoms (Rueda, Artazcoz and Navarro 2008). However, lifestyles and health-related behaviors tend to favor women's health results rather than men`s. Smoking and alcohol consumption account for a high proportion of gender differences in mortality around the world (McCartney et al. 2011). As regards obesity, it has been found that higher income levels reduce female but not male prevalence (García Villar and Quintana-Domeque 2009). The latter asymmetric results might be due to social pressure on the body image or might be because women who enjoy a better socioeconomic position are more committed than men to doing regular exercise or following a better diet as preventive behavior (Borders, Rohrer and Cardarelli 2006; Jeffery et al. 1991). When attention focuses on the evolution of gender health gaps with aging, some studies report contradictory results, pointing to either an increasing or decreasing pattern depending on the health indicator considered (Carmel 2019) and with considerable cross-country variability (Uccheddu et al. 2019), revealing the need for additional research on this subject.

The interventions through which the welfare state can reduce inequalities between men and women include policies which encourage female participation in the job market, providing facilities so as to better combine family and paid work, support for different models of family, providing public care services for children, etc. The impact of these equalitarian policies on reducing gender health inequalities among the adult population has been the subject of research (Borrell et al. 2014), however, at older ages the roles change: working is no longer such a common activity and there is no need to raise children. Given their everincreasing vulnerability, greater dependence, and reduced social participation, the protective role played by the state and family support become more relevant at this stage of life, even more so for the oldest old, with the pension system and the social provision of care emerging as the key instruments of intervention.

Some authors point to welfare states' social policy responsiveness to the general aging population process, which may explain a recent pro-elderly bias in the orientation of welfare spending. At the same time, the demands of other areas of social spending compete with those of aging: female inclusion in the job market and the difficulties involved in terms of reconciling work and family tasks, the ever-growing instability of family structures with rising divorce rates and single-parent families, and long-term unemployment (Bonoli 2007), particularly in Southern and Eastern European economies. Welfare state 
regimes have an important explanatory power of the between-country variability in social spending patterns (Tepe and Vanhuysse 2010), and also in the consideration of care as a matter of family or a state responsibility (Ferrera 1996; Daly and Lewis 2000), leading to different models of care provision for the elderly. On the one hand, Southern countries devote fewer public resources to the attention of new social risks and families and they are more focused on aging, while the opposite occurs in Scandinavian economies (Tepe and Vanhuysse 2010). On the other hand, Central European states and Anglo-Saxon countries are less attached to traditions and care provided by family is less frequent (Ferrera 1996). In regimes where family provision of care for older relatives is more frequent, this burden is mainly borne by women, with the subsequent increase in anxiety and depressive symptoms developed by the care provider adding yet further to the gender gap in health.

Recently, a greater link between socioeconomic position and health for women than for men was reported in Southern and Central European states, with no difference being found between men and women in Scandinavian countries (Uccheddu et al. 2019). Focusing on depressive symptoms, Hansen, Slagsvold and Veenstra (2017) reported a higher female than male prevalence in all the countries analyzed, although their results point to a wide gap between Scandinavian countries and Eastern European countries. Previous cross-country research has reported a greater prevalence of low levels of self-rated health for men and women in Eastern European regimes (Deaton 2008), although there is a lack of research on these countries, and most published studies do not include them in the cross-country comparative analysis. Gender differences appear to be greater in Southern European countries (Aguilar-Palacio et al. 2018) although no general patterns were found in an extensive review carried out by (Read, Grundy and Foverskov 2015) on the relation between socioeconomic position and self-rated health by gender.

The lack of conclusive results on the influence of welfare state regimes on gender inequalities in health among the European elderly, and its age-related pattern, forms the basis of our research. We contribute to the current literature on gender inequalities in health and aging by addressing the following research questions:

1. Is there a general gender health gap at older ages across Europe?

2. Is there a universal association between the gender health gap and age among the older European population, which grows wider or narrower with age, or does it depend on the type of welfare regime?

The study of such questions is highly relevant. As older people age their health needs grow and the provision of care becomes more relevant for their self-perception of health. We control for socioeconomic position and lifestyles when accounting for gender differences in health across European countries. This may therefore help to better identify which models of care provision, represented by welfare states types, are more successful in terms of reducing gender inequalities in health among the elderly in Europe.

\section{Methods}

\subsection{Data}

We used microdata from the 6th wave of the Survey of Health, Ageing and Retirement in Europe (SHARE), carried out in 2015 across 18 countries (Börsch-Supan 2017). SHARE 
is a valuable survey designed to help with the study of aging in Europe, as it collects wideranging information on the physical and mental health, life satisfaction and wellbeing of people aged 50 and above, across a growing number of countries in Europe. It also covers a variety of areas such as socio-economic conditions, social support, and social networks. (See Börsch-Supan et al. 2013 for methodological details).The sixth wave provides representative, cross-nationally comparable panel data on more than 66,000 individuals who live in residential households and who were born in 1964 or earlier. In our analysis, 17 European countries were considered (Israel was excluded due to its non-European status) and a total of 59,539 non-institutionalized elderly people made up the selected sample (see Table 1).

\subsection{Variables}

Self-rated health (SRH) was chosen as an outcome variable. This indicator has a long tradition in the study of social determinants of health since a strong correlation has been shown to exist between SRH and mortality among the general population as well as among the elderly in particular; (Mossey and Shapiro 1982; Lee 2000). In this survey, respondents were asked: "would you say your health is ....?" They were required to choose from "excellent", "very good", "good", "fair" and "poor". This variable was dichotomized into two categories: good health (excellent, very good or good) and poor health (fair or poor) as usual (Manderbacka, Lahelma and Martikainen 1998).

We considered three types of individual-level information: demographic, socioeconomic and health-related behaviors. Age, gender, relationship status and living in a big city are the demographic variables. Age was introduced into the analysis by considering four age-related groups: from 50 to 59 , from 60 to 69, from 70 to 79 and 80 and over. Relationship status considers whether individuals have a partner or not. We took into consideration the presence of a partner as a form of social capital as it is believed to reduce the occurrence of depressive symptoms and improve SRH. Nevertheless, for older women, this does not have to be fulfilled (or maintained) since the likelihood of having a partner with a disability increases with age and women are more frequently primary caregivers than men (Feld et al. 2006; Noël-Miller 2011). Hence, there may be a gender different effect on elderly people's SRH. In addition, living in a big city environment gives the elderly easier access to better health services. In contrast, living in less developed rural areas may reduce the local availability of quality health attention added to which the lack of public transport may particularly affect the health of the elderly.

The socioeconomic variables chosen were education, household net income and difficulty making ends meet. There is no consensus among researchers regarding the choice

Table 1 Countries by welfare state regimes

\begin{tabular}{llll}
\hline Social democratic & Bismarckian & Southern & Eastern \\
\hline Sweden & Germany & Greece & Croatia \\
Denmark & France & Italy & Czech Republic \\
& Switzerland & Portugal & Estonia \\
& Austria & Spain & Poland \\
& Luxembourg & & Slovenia \\
& Belgium & & \\
\hline
\end{tabular}


of the best variable to analyze the influence of the socioeconomic position on the elderly health. Occupational social class does not seem adequate since most elderly population is not working anymore or a high proportion of elder women never worked. Individual income does not take into account the influence of other sources of income in the household and can underestimate individual's purchasing power. Moreover, educational attainment can be skewed among older people due to the low average level of education. Thus, it is common to consider more than one dimension of socioeconomic determinants (Huisman, Kunst and Mackenbach 2003; Rueda, Artazcoz and Navarro 2008) and the educational level is complemented by household net income and difficulty making ends meet.

For education, in accordance with the International Standard Classification of Education (ISCED), we took into account three levels, depending on the highest academic attainment: primary or none, secondary (including lower secondary or second stage of basic education, upper secondary education and post-secondary non-tertiary education) and tertiary (first or second stage of tertiary education). As regards household income, we computed quartiles of the net total household income in each country and created a dummy variable for each category. We also considered whether difficulty making ends meet was reported, as a measure of subjective poverty.

Healthy lifestyles can prevent chronic diseases and can slow physical and cognitive decline (Speake, Cowart and Pellet 1989). Therefore we included some variables related to healthy or unhealthy behaviors. We considered: sedentary life, when individuals hardly ever or never do activities requiring a moderate level of energy; alcohol consumption, when they drink six or more alcoholic drinks once or more per month; overweight, if individuals have a body mass index (BMI) greater than or equal to 25, and smoking, for those who are or were smokers. We also considered whether the elderly have complementary health insurance.

As regards welfare state regimes, four types were included in our study: Bismarckian, Scandinavian or Social Democratic, Southern and Eastern welfare states (See Table 1). Ferrera's classification (Ferrera 1996) considered Scandinavian, Bismarckian, AngloSaxon and Southern countries, whereas we only took into account three of them since there are no Anglo-Saxon states in our data, although we did add the ex-socialist economies.

A wide range of empirical analyses has adopted this welfare state classification (Eikemo et al. 2008a, b, c; Guarnizo-Herreño et al. 2017). It has received some criticism arguing that it fails to take into consideration women and the role of the family in the provision of welfare. Indeed, new indexes were developed (Bambra 2004) which take into account factors such as the female labor participation rate, maternity leave compensation, its duration and average female wage and the resulting gender-sensitive classification does not, however, significantly differ from the standard welfare typology.

\subsection{Statistical Procedure}

Various multi-level random intercept logistic regression analyses were estimated, and the Stata 13 software package was employed to carry out the statistical procedure. Data were hierarchized into two levels: individuals (level 1) nested within 17 countries (level 2). The reference person in the analysis is a male aged between 50 and 59, having a partner and living in a small town. He has no education or primary education and his household income level is higher than the third quartile of his country. When regimes were introduced into the analysis, Eastern countries were the reference category. 
As we used a multilevel logistic model and the variances of both levels are not on the same scale, we made use of the latent variable approach (Gelman and Hill 2007; Snijders, Tom and Bosker 2012). This technique assumes the variance of level 1 is the variance of a standard logistic distribution, $\pi^{2} / 3=3.29$, while the country-level residuals are normally distributed, and the value of the variance can be calculated by the fitted model $\left(\sigma_{0}^{2}\right)$. Therefore, the percentage of the total variance attributed to level 2 is obtained by the expression: $\frac{\sigma_{0}^{2}}{\sigma_{0}^{2}+3.29} \times 100$.

First, we fitted a null model (Model 1), which provided an initial estimation of the country-level variance in bad health. Secondly, we introduced gender and age information in Model 2. Next, individual level variables which explain demographic and socioeconomic characteristics, as well as the health-related behaviors of Europeans, were considered. Finally, in Model 4, we added welfare state regimes to determine their influence on the between- country variability. Results are presented in Table 3. In addition, we studied interactions between gender and welfare state. Multilevel results showed that gender health gap was significantly different in some welfare state regimes. Therefore, we stratified by welfare regime, and new multilevel estimations were conducted, one for each group of countries, except for Social Democratic states since there were only two in our sample. Results can be found in Table 4. Finally, new multilevel models were fitted for each welfare state type in order to gain deeper insight into the gender health gap throughout the aging process, by considering gender-age multiplicative dummy variables (see Table 5).

To assess the relevance of the independent variables in each model, we used the Deviance Information Criterion (DIC) which compares the deviances of the models by means of a Chi-square test. Generally, a reduction of the deviance means an improvement in the model (Hox 2010).

\section{Results}

Our sample is composed of 59,539 individuals, aged 50 years and older and who come from 17 European countries, with 55.3\% of the sample being women. Table 2 summarizes the respondents' characteristics. As can be seen, $60.9 \%$ of the sample report good health, while $39.1 \%$ report health problems. The data suggest a relation between bad health and being female. While $40.5 \%$ of women say they have poor health, only $37.3 \%$ of men do. As regards welfare states, the Scandinavian countries report the fewest health problems, only $23.6 \%$, while in the Eastern European regimes over 50\% of respondents report health problems. In all groups of countries, women report suffering more health problems than men. There are major differences in the educational structure of individuals among welfare regimes, particularly in the case of the Southern European countries, where over $47 \%$ of the population have no formal studies or have only completed primary education. In other welfare states, this figure accounts for $15 \%$ or less of the whole country.

Table 3 shows the main estimation results, reporting odds ratios. Starting with the null model (Model 1), there is a significant inequality in SRH across countries (0.399, $\mathrm{SE}=0.137), 10.8 \%$ of which is attributable to differences between countries. When gender and age-related information was considered, a significant gender gap emerged, as well as a negative age gradient, since the older the people the greater the risk of reporting poor health. Both effects remained strongly significant when different covariates were added. Socioeconomic characteristics were introduced into the estimation and many were a source of health inequalities. Thus, education and the household's level 


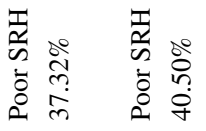

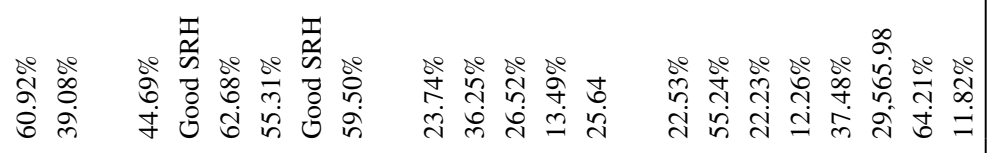

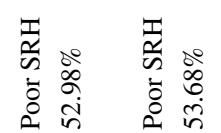

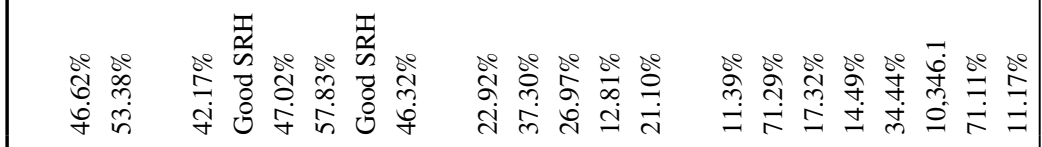

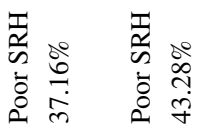

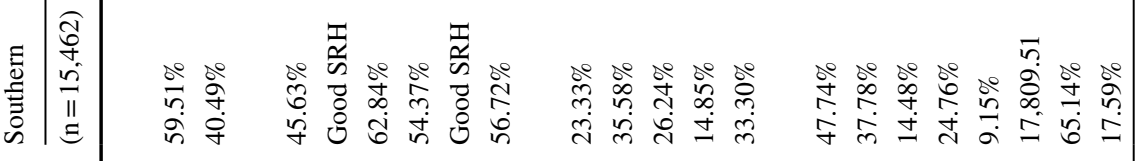

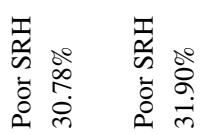

券

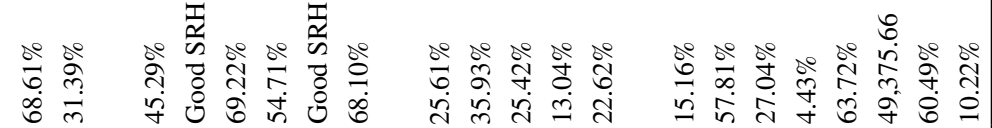

至

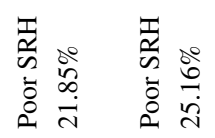

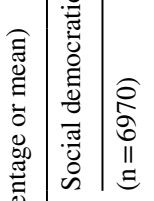

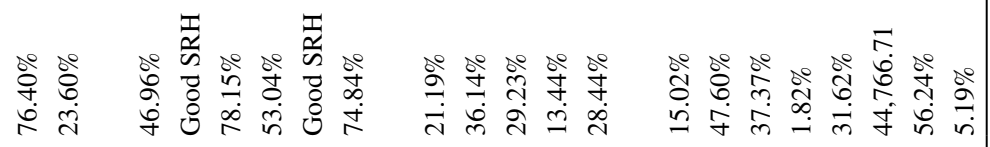

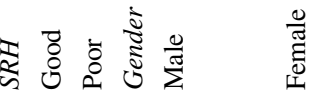

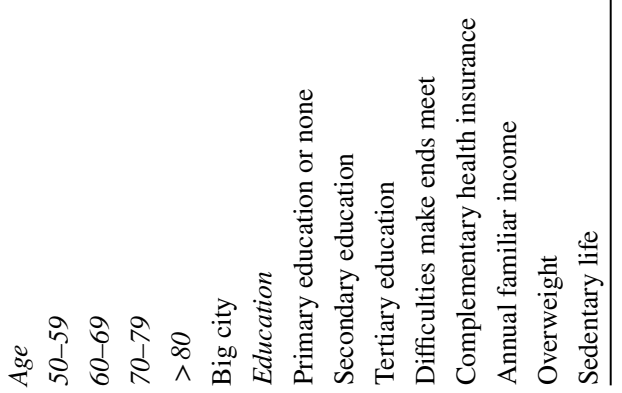




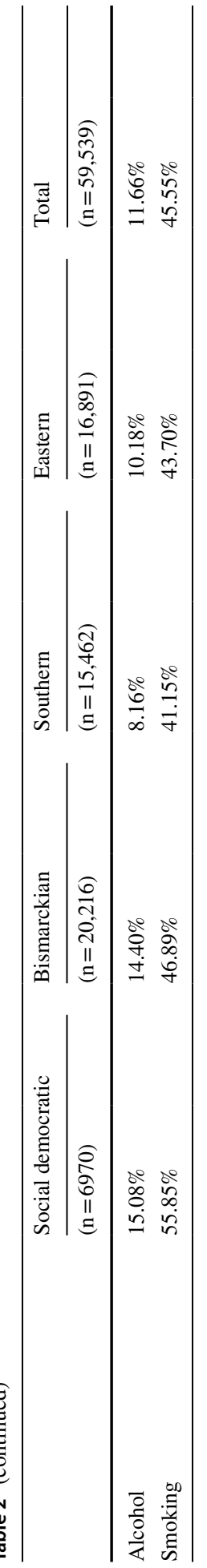


Table 3 Multilevel regression analyses of fair/poor self-rated health (Odds ratio)

\begin{tabular}{|c|c|c|c|c|}
\hline & $\begin{array}{l}\text { Model } 1 \\
(\mathrm{n}=59,539)\end{array}$ & $\begin{array}{l}\text { Model } 2 \\
(\mathrm{n}=59,539)\end{array}$ & $\begin{array}{l}\text { Model } 3 \\
(\mathrm{n}=59,539)\end{array}$ & $\begin{array}{l}\text { Model } 4 \\
(\mathrm{n}=59,539)\end{array}$ \\
\hline Intercept & $0.636 * *$ & $0.323 * * *$ & $0.271 * * *$ & $0.486^{* *}$ \\
\hline \multicolumn{5}{|l|}{ Gender } \\
\hline Male & & 1.000 & 1.000 & 1.000 \\
\hline Female & & $1.147 * * *$ & $1.085 * * *$ & $1.085 * * *$ \\
\hline \multicolumn{5}{|l|}{ Age } \\
\hline $50-59$ & & 1.000 & 1.000 & 1.000 \\
\hline $60-69$ & & $1.444^{* * *}$ & $1.370 * * *$ & $1.370 * * *$ \\
\hline $70-79$ & & $2.543 * * *$ & $2.143 * * *$ & $2.143^{* * *}$ \\
\hline$>80$ & & $4.734 * * *$ & $3.020 * * *$ & $3.020 * * *$ \\
\hline Partner & & & 0.970 & 0.970 \\
\hline Big city & & & $0.954 *$ & $0.955^{*}$ \\
\hline \multicolumn{5}{|l|}{ Education } \\
\hline Primary education or none & & & 1.000 & 1.000 \\
\hline Secondary education & & & $0.704 * * *$ & $0.704 * * *$ \\
\hline Tertiary education & & & $0.474 * * *$ & $0.474 * * *$ \\
\hline Complementary health insurance & & & $0.826 * * *$ & $0.825 * * *$ \\
\hline Difficulties make ends meet & & & $1.875^{* * *}$ & $1.873 * * *$ \\
\hline \multicolumn{5}{|l|}{ Annual family income } \\
\hline$<1$ st quartile & & & $1.546^{* * *}$ & $1.547 * * *$ \\
\hline 1st quartile- 2 nd quartile & & & $1.441 * * *$ & $1.441 * * *$ \\
\hline 2nd quartile-3rd quartile & & & $1.288 * * *$ & $1.288 * * *$ \\
\hline$>3$ rd quartile & & & 1.000 & 1.000 \\
\hline Overweight & & & $1.388 * * *$ & $1.388 * * *$ \\
\hline Sedentary life & & & $4.354 * * *$ & $4.356^{* * * *}$ \\
\hline Alcohol & & & $0.776^{* * *}$ & $0.776^{* * *}$ \\
\hline Ever smoked & & & $1.206 * * *$ & $1.205^{* * *}$ \\
\hline \multicolumn{5}{|l|}{ Welfare state regime } \\
\hline Eastern & & & & 1.000 \\
\hline Southern & & & & $0.521 *$ \\
\hline Bismarckian & & & & $0.439 * *$ \\
\hline Social democratic & & & & $0.306^{* *}$ \\
\hline Between country variation (SE) & $0.399(0.137)$ & $0.452(0.156)$ & $0.386(0.133)$ & $0.221(0.077)$ \\
\hline Individual level percentage of total variance & $89.18 \%$ & $87.92 \%$ & $89.50 \%$ & $93.71 \%$ \\
\hline Country level percentage of total variance & $10.82 \%$ & $12.08 \%$ & $10.50 \%$ & $6.29 \%$ \\
\hline Deviance information criterion & $74,853.91$ & $71,620.46$ & $66,393.43$ & $66,384.07$ \\
\hline
\end{tabular}

$* p<0.05$

$* * p<0.01$

$* * * p<0.001$ 
Table 4 Multilevel regression analyses ${ }^{\mathrm{a}}$ of fair/poor self-rated health ${ }^{\mathrm{b}}$ by welfare state regime (Odds ratios)

\begin{tabular}{|c|c|c|c|c|}
\hline & $\begin{array}{l}\text { Social democratic } \\
(\mathrm{n}=6,970)\end{array}$ & $\begin{array}{l}\text { Bismarckian } \\
(n=20,216)\end{array}$ & $\begin{array}{l}\text { Southern } \\
(\mathrm{n}=15,462)\end{array}$ & $\begin{array}{l}\text { Eastern } \\
(\mathrm{n}=16,891)\end{array}$ \\
\hline Intercept & $0.158 * * *$ & $0.240 * * *$ & $0.240 * * *$ & $0.366^{* * *}$ \\
\hline \multicolumn{5}{|l|}{ Gender } \\
\hline Male & 1.000 & 1.000 & 1.000 & 1.000 \\
\hline Female & $1.199^{* *}$ & 0.997 & $1.358 * * *$ & 0.955 \\
\hline \multicolumn{5}{|l|}{ Age } \\
\hline $50-59$ & 1.000 & 1.000 & 1.000 & 1.000 \\
\hline $60-69$ & 0.942 & $1.134^{* *}$ & $1.669 * * *$ & $1.535^{* * *}$ \\
\hline $70-79$ & 1.024 & $1.554 * * *$ & $3.077 * * *$ & $2.703^{* * *}$ \\
\hline$>80$ & $1.530^{* * *}$ & $2.031 * * *$ & $4.454 * * *$ & $4.143^{* * *}$ \\
\hline Partner & 0.954 & 1.075 & $0.868^{* *}$ & 1.075 \\
\hline Big city & 1.010 & 1.053 & 0.943 & $0.859^{* *}$ \\
\hline \multicolumn{5}{|l|}{ Education } \\
\hline Primary education or none & 1.000 & 1.000 & 1.000 & 1.000 \\
\hline Secondary education & $0.737 * * *$ & $0.646 * * *$ & $0.708 * * *$ & $0.777 * * *$ \\
\hline Tertiary education & $0.566 * * *$ & $0.482 * * *$ & $0.529 * * *$ & $0.419^{* * *}$ \\
\hline Complementary health insurance & $0.774 * * *$ & $0.751 * * *$ & $0.820^{* *}$ & $1.133^{*}$ \\
\hline Difficulties make ends meet & $1.889^{* *}$ & $2.133 * * *$ & $1.833^{* * *}$ & $2.074 * * *$ \\
\hline \multicolumn{5}{|l|}{ Annual family income } \\
\hline$<1$ st quartile & $2.215^{* * *}$ & $2.080^{* * *}$ & $1.151^{*}$ & $1.464^{* * *}$ \\
\hline 1st quartile- 2 nd quartile & $1.884 * * *$ & $1.613^{* * *}$ & $1.194 * *$ & $1.480^{* * *}$ \\
\hline 2nd quartile-3rd quartile & $1.278^{*}$ & $1.300 * * *$ & $1.155^{* *}$ & $1.384 * * *$ \\
\hline$>$ 3rd quartile & 1.000 & 1.000 & 1.000 & 1.000 \\
\hline Overweight & $1.535^{* * *}$ & $1.402 * * *$ & $1.348^{* * *}$ & $1.329^{* * *}$ \\
\hline Sedentary life & $7.004 * * *$ & $4.782 * * *$ & $3.551 * * *$ & $4.624 * * *$ \\
\hline Alcohol & 0.847 & $0.823 * * *$ & $0.660 * * *$ & $0.753^{* * *}$ \\
\hline Smoking & $1.264 * * *$ & $1.242 * * *$ & $1.175^{* * *}$ & $1.197 * * *$ \\
\hline Deviance information criterion & & $21,966.81$ & $17,469.56$ & $19,626.09$ \\
\hline
\end{tabular}

$* * * p<0.001 ; * * p<0.01 ; * p<0.05$

${ }^{a}$ Social democratic countries were studied by a logit (not multilevel) model

${ }^{\mathrm{b}}$ Adjusted for all the covariates

of income significantly reduce the odds of reporting bad health. In contrast, smoking, being overweight or leading a sedentary life damage health. However, having complementary health insurance, as well as a good socioeconomic status (no difficulty making ends meet or a higher familiar income), reduce the odds of reporting bad health.

In Model 4, welfare state regimes were added to the analysis. This addition improves the estimation since the deviance is significantly lower than Model $3\left(\chi^{2}=9.356 ; \mathrm{df}=3\right.$; p-value $<0.025)$ and reduces the country level variance. Thus, it can be said that part of the between-country health inequalities can be attributed to welfare state regimes. We found that in general, people aged 50 and over in the Southern, Bismarckian and Social Democratic countries report better health than in the Eastern European countries. (Odds ratios: $0.52,0.44$ and 0.31 respectively). 
Table 5 Multilevel regression analyses ${ }^{\mathrm{a}}$ of fair/poor self-rated health ${ }^{\mathrm{b}}$ by welfare state regime (Odds ratios)

\begin{tabular}{|c|c|c|c|c|}
\hline & $\begin{array}{l}\text { Social democratic } \\
(n=6,970)\end{array}$ & $\begin{array}{l}\text { Bismarckian } \\
(n=20,216)\end{array}$ & $\begin{array}{l}\text { Southern } \\
(\mathrm{n}=15,462)\end{array}$ & $\begin{array}{l}\text { Eastern } \\
(\mathrm{n}=16,891)\end{array}$ \\
\hline Intercept & $0.150 * * *$ & $0.244 * * *$ & $0.244 * * *$ & 0.351 \\
\hline Male between 50 and 59 & 1.000 & 1.000 & 1.000 & 1.000 \\
\hline Female between 50 and 59 & 1.317 & 0.964 & $1.300 * *$ & 1.016 \\
\hline Male between 60 and 69 & 0.987 & 1.095 & $1.652 * * *$ & $1.661 * * *$ \\
\hline Female between 60 and 69 & 1.202 & 1.124 & $2.173 * * *$ & $1.47 * * *$ \\
\hline Male between 70 and 79 & 1.108 & $1.540 * * *$ & $3.050 * * *$ & $2.785 * * *$ \\
\hline Female between 70 and 79 & $1.27 *$ & $1.505 * * *$ & $4.009 * * *$ & $2.693 * * *$ \\
\hline Male 80 and over & $1.653 * *$ & $1.966 * * *$ & $3.914 * * *$ & $3.961 * * *$ \\
\hline Female 80 and over & $1.898 * * *$ & $2.010 * * *$ & $6.556 * * *$ & $4.366 * * *$ \\
\hline
\end{tabular}

$* * * p<0.001 ; * * p<0.01 ; * p<0.05$

a: Social democratic countries were studied by a logit (not multilevel) model

b: Adjusted for all the covariates

When we stratified by welfare state typology (Results are shown in Table 4), we found different patterns for health inequalities among elderly European people for each welfare state typology. In the Bismarckian and Eastern European states, being female is not a significant variable when reporting fair or poor health. Nevertheless, in the Southern and Scandinavian regimes, women are more likely to report that they suffer from bad health than men. As regards age, the older the individual, the more likely they are to report poor health in all welfare regimes except the Social Democratic, where this is only true for the very old. The increase in the odds ratio of reporting poor health for the older age-related groups is particularly intense in the Southern and Eastern European countries where the odds of declaring bad health among the much older ( 80 and above) are over four times greater than for the youngest group, that is, people between 50 and 59. (Odds-ratio 4.454 and 4.143, respectively).

Finally, Table 5 shows the odds ratios of reporting poor health for each welfare state type, when considering interactions between gender and age and adjusting for the rest of covariates. Compared to the reference age group, men between 50 and 59, in the Bismarckian welfare state type, both old men and women report a similar age-related gradient in their odds ratios of reporting poor health. Moreover, the eldest elder group experience an odds of reporting bad health that is twice times higher than that of the youngest group, (odds ratio:1.966 for men and 2.010 for women). In the Social Democratic countries instead, we did not find a significant aged-related gradient, neither male nor female. There was a significant increase in the odds ratio of referring poor health only for the older than 80 years group and it was higher for women than men (odds ratio 1,898 and 1,653 respectively).

The most outstanding age-related pattern was found for the elderly in the Eastern and Southern countries, although there were important differences between these two welfare state types with respect to the presence of a gender-health gap. In the Eastern economies, both male and female elderly people experience higher odds ratios of referring fair/poor health when they are older, but the increase is higher for women than for men and it is for people aged 80 and more, when a clear female gender health gap emerges (odds ratios 3.961 for men and 4.366 for women). On the contrary, in the Southern countries, there is 
a significant gender health gap for all the age-related population groups, and its magnitude rises as we consider more aged people. In these countries, the odds of reporting fair/ poor health for females aged 80 and above are more than six times higher than that of men between 50 and 59 years (odds-ratio, 6.56). Figure 1 represents these results in a more intuitive manner.

\section{Discussion}

The aim of our analysis was to gain a deep insight into the links among gender, age and health for elderly people in Europe, and how welfare state regimes influence these relations. Various multilevel models were fitted with data from 17 European countries, provided by SHARE. Despite the suitability of this survey to study health differentials in older people in Europe, the data provided for Spain may be conditioned because the province of Girona is over-represented.

After adjusting for a wide range of covariates, when we studied the pooled sample our results showed that older people in Eastern and Southern economies report poorer health than in Bismarckian and in Social democratic countries. This confirms a general pattern previously reported on repeated occasions for the adult population as a whole (Eikemo et al. 2008a, b, c). Suggested explanations for this, among others, are related to the extensive welfare provision and social cohesion of Social Democratic countries (Bambra 2006) compared to the fragmentary welfare provision system of Southern European countries or the limited health service provision and abandonment of universalism that is typical of communism in Eastern economies (Eikemo, Bambra, Joyce and Dahl 2008a, b, c). Some caution has to be taken when interpreting cross-country comparisons using SRH outcomes due to the influence of cultural differences in health perceptions (Jürges 2010). What is more, the cross-country variability attributed to welfare state typologies may be better
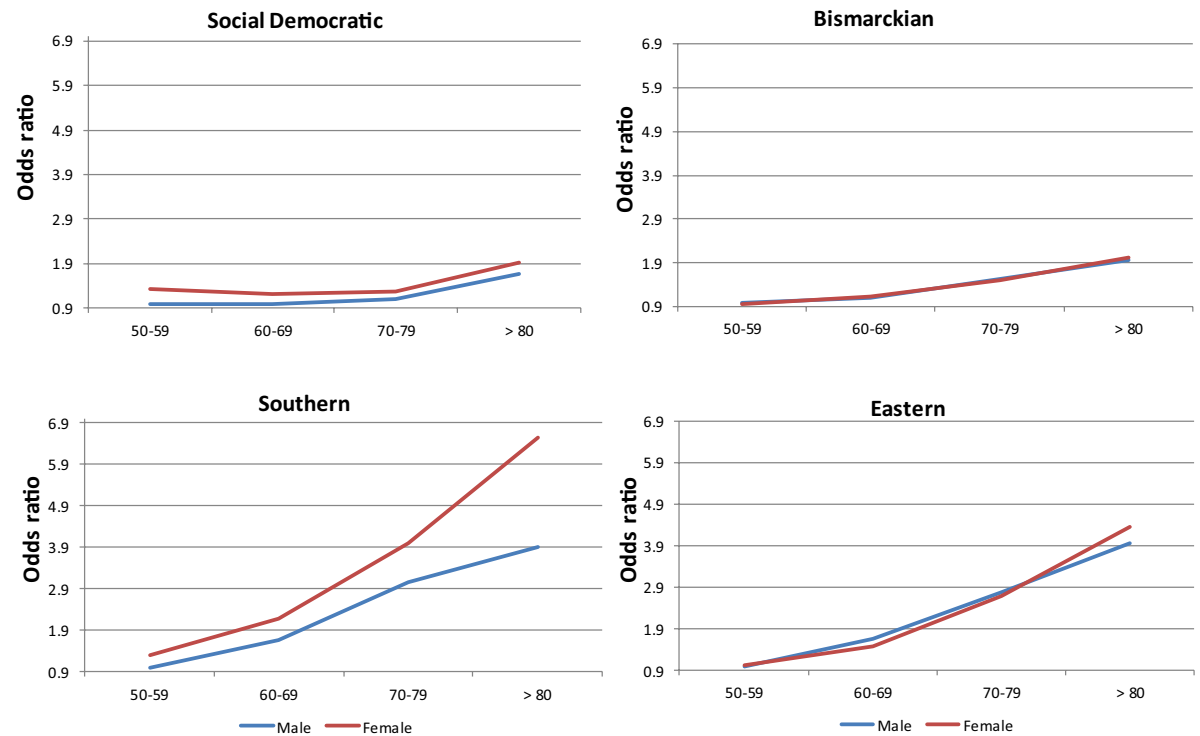

*ORs are calculated using 50-59 year old men as the reference category

Fig. 1 Fair/poor health by age* 
related to between-countries national income differences than to inequalities in public welfare provision. However, it should be pointed out that previous research has noted that the relationship between socioeconomic conditions and the older population's subjective health is weaker than for the general adult population (Beckett 2000), thereby reducing the significance of this limitation.

Summing up our results, an adverse age-related gradient was found for the health of male and female elderly European population, leading to a significant increase in the likelihood of reporting poor health for the very old (80 years and over) across the whole continent. Several interesting differences were found among welfare states since they account for an important part of the total between-country variability. The age-related deterioration in SRH found for the European elderly was significantly higher in Eastern and Southern countries than in Bismarckian and Social Democratic regimes. While we did not find any gender inequalities in Bismarckian and Eastern economies, in Southern regime countries there was a significant gender health gap for all age-related groups, a gap that widened rapidly when we considered the oldest age groups.

The decline in SRH with age is not a general conclusion to come out of prior research, with contradictory results emerging from different empirical analyses (Acciai 2018; Verropoulou 2012). In our study, this trend is not systematic for all age-related groups in the Social Democratic regime. There, it is highly significant only for the very old (over 80 years), who also show the highest gender inequalities in SRH in that regime. Thus, it seems that this highly protective welfare state succeeds in reducing gender and age-related inequalities in health for the early older people.

There is a well-documented gap between the health of Central and Eastern Europeans when compared to Western Europeans, particularly since the latter stages of the communist regime and during the transition to market economies. This process was accomplished at the expense of a significant deterioration in public health and also had a major impact on social policy (Carlson 1998; Deacon 2000). Various cross-country comparisons have highlighted this difference, both for mortality rates and SRH, when considering the whole adult population (Carlson 1998; Guarnizo-Herreño et al. 2017), but also for the elderly. Moreover, in the case of the latter, the gap widens as they get older, as has recently been noted (Obrizan 2018). Our results confirm this age-related pattern of decreasing SRH with age, although we did not find any evidence of a gender gap in reported health among elderly Eastern Europeans for any age group.

Various reasons may be pointed out to explain the poorer results in health found for the elderly in Southern countries. The labor participation of women is traditionally lower than in other Western countries, especially for those aged 55 and over, with unpaid female family labor being widespread. There is also substantial occupational segregation against women in the job market which leads to lower average wage levels for females (Garcia-Prieto and Gómez-Costilla 2017). This makes older Southern European women more dependent on protection from the general pension system than they are in other welfare regimes such as the Social Democratic or Bismarckian. In these circumstances, it has been suggested that a generous system of minimum pensions benefits women more than men (Högberg 2018; Esser and Palme 2010) although the Southern welfare regime is characterized by a lower level of minimum pensions and a fragmentary provision system.

Southern European countries are also characterized by the greater importance attached to traditions and to stronger family support than in other regimes (Ferrera 1996). Thus, the percentage of elderly people living in nursing homes is lower in Southern European states, where the provision of care for dependent partners at home is more frequent. This may lead to an overrepresentation of older people reporting poor health, given that our study 
only focuses on non-institutionalized older people. This is a common limitation in most published studies. Since there is a lack of information about institutionalized elderly people's health for certain countries in the SHARE dataset, this group of population is often excluded from the analyses.

The countries of the Southern welfare regime have the oldest population. Moreover, these countries present a gender paradox: life expectancy for women is higher than for men although female life expectancy without activity limitation is lower than male's. As a consequence there is a large group of the much older, composed by more women than men, who are more limited in their activity than men and who report worse health (SerranoAlarcón and Perelman 2017). All these factors may be explaining the large gender health gap encountered for this group.

In the case of the Bismarckian regime, it is worth noting the good results this cluster often obtains in cross-country comparisons based on SRH. For the whole adult population, no gender health gap was found in prior research (Bambra et al. 2009), a result confirmed in our analysis for the elderly. Their pension system is generous but is an earning-related type, which benefits men's health more, since they earn higher wages on average. In contrast, the provision of formal care is higher than in Southern countries, thus alleviating the charge of taking care of the male partner at home. All of these considerations are not conclusive and deserve deep further analysis.

Finally, it should be pointed out that our research has some limitations. Firstly, the use of a cross sectional design limits the interpretation of our results since causal inference cannot easily be drawn and it does not allow us to study the evolution of the elderly's health as they age. Despite this limitation, our study provides a comprehensive analysis of differences in SRH among the age-related population groups at a given moment of time and its relation to welfare state regime typologies. Secondly, SRH is a subjective measure of health and this can generate some concerns especially when our study has a gender perspective. The gender gap in SRH may contain a gender-specific bias since women take into account objective and subjective issues of health (Benyamini, Leventhal and Leventhal 2000), although recent studies (Zajacova, Huzurbazar and Todd 2017) has shown that SRH is an equally good predictor for both genders. Moreover, when a wide geographical area is considered, social and cultural differences between countries can bias how individuals perceive their health (Jürges 2007), although there is not a general conclusion (Desesquelles, Egidi and Salvatore 2009). In order to overcome the doubts generated by the subjectivity of the SRH, we performed a sensitivity analysis considering the following three indicators as alternative health outcomes: difficulty doing at least one of six activities of daily living, problems with at least one of seven instrumental activities of daily living, and some limitation with mobility, arm function and fine motor. All of them are indicators of physical health provided by the survey. The results obtained with these outcomes are similar to those generated by the analysis carried out with self-rated health.

\section{Conclusions}

The study has shown that there are major differences among the European elderly in terms of SRH related to age, gender and country that deserve to be pointed out. Further research is needed to shed light on the mechanisms through which certain welfare state types have succeed in reducing such inequalities. When considering age, the very old are the most vulnerable group, with the problem proving to be particularly serious in Eastern and Southern 
Europe, and in the latter case, especially for women. Initiatives aimed at improving specialized support for these population groups emerge as a priority in such countries.

Acknowledgements The authors thank financial support from Consejería de Educación de la Junta de Castilla y León (VA112G19). This paper uses data from SHARE Wave 6 (DOIs: https://doi.org/10.6103/ SHARE.w6.710), see Börsch-Supan et al. (2013) for methodological details. (1) The SHARE data collection has been funded by the European Commission through FP5 (QLK6-CT-2001-00360), FP6 (SHARE-I3: RII-CT-2006-062193, COMPARE: CIT5-CT-2005-028857, SHARELIFE: CIT4-CT-2006-028812), FP7 (SHARE-PREP: GA N²11909, SHARE-LEAP: GA N²27822, SHARE M4: GA N²61982, DASISH: GA N²83646) and Horizon 2020 (SHARE-DEV3: GA N${ }^{\circ} 676536$, SHARE-COHESION: GA N ${ }^{\circ} 870628$, SERISS: GA N ${ }^{\circ} 654221$, SSHOC: GA N ${ }^{\circ} 823782$ ) and by DG Employment, Social Affairs \& Inclusion. Additional funding from the German Ministry of Education and Research, the Max Planck Society for the Advancement of Science, the U.S. National Institute on Aging (U01_AG09740-13S2, P01_AG005842, P01_AG08291, P30_AG12815, R21_AG025169, Y1-AG-4553-01, IAG_BSR06-11, OGHA_04-064, HHSN271201300071C) and from various national funding sources is gratefully acknowledged (see https:// www.share-project.org).

Open Access This article is licensed under a Creative Commons Attribution 4.0 International License, which permits use, sharing, adaptation, distribution and reproduction in any medium or format, as long as you give appropriate credit to the original author(s) and the source, provide a link to the Creative Commons licence, and indicate if changes were made. The images or other third party material in this article are included in the article's Creative Commons licence, unless indicated otherwise in a credit line to the material. If material is not included in the article's Creative Commons licence and your intended use is not permitted by statutory regulation or exceeds the permitted use, you will need to obtain permission directly from the copyright holder. To view a copy of this licence, visit http://creativecommons.org/licenses/by/4.0/.

\section{References}

Acciai, F. (2018). The age pattern of social inequalities in health at older ages: Are common measures of socio-economic status interchangeable? Public Health, 157, 135-141. https://doi.org/10.1016/j. puhe.2018.01.002.

Adeline, A., \& Delattre, E. (2017). Some microeconometric evidence on the relationship between health and income. Health Economics Review, 7(1), 27. https://doi.org/10.1186/s13561-017-0163-5.

Aguilar-Palacio, I., et al. (2018). Self-rated health in Europe and its determinants: Does generation matter? International Journal of Public Health, 63(2), 223-232. https://doi.org/10.1007/s00038-018-1079-5.

Arber, S., \& Cooper, H. (1999). Gender differences in health in later life: The new paradox? Social Science and Medicine, 48(1), 61-76.

Avendano, M., Jürges, H., \& Mackenbach, J. P. (2009). Educational level and changes in health across Europe: Longitudinal results from SHARE. Journal of European Social Policy, 19(4), 301-316. https ://doi.org/10.1177/1350506809341512.

Bambra, C. (2004). The worlds of welfare: illusory and gender blind? Social Policy and Society, 3(3), 201211. https://doi.org/10.1017/S147474640400171X.

Bambra, C. (2006). Health status and the worlds of welfare. Social Policy and Society, 5(01), 53. https://doi. org/10.1017/S1474746405002721.

Bambra, C., et al. (2009). Gender, health inequalities and welfare state regimes: A cross-national study of 13 European countries. Journal of Epidemiology and Community Health, 63(1), 38-44. https://doi. org/10.1136/jech.2007.070292.

Bambra, C., Netuveli, G., \& Eikemo, T. A. (2010). Welfare state regime life courses: The development of western European welfare state regimes and age-related patterns of educational inequalities in selfreported health. International Journal of Health Services, 40(3), 399-420. https://doi.org/10.2190/ HS.40.3.b.

Beckett, M. (2000). Converging health inequalities in later life-An artifact of mortality selection? Journal of Health and Social Behavior, 41(1), 106-119. https://doi.org/10.2307/2676363.

Benyamini, Y., Leventhal, E. A., \& Leventhal, H. (2000). Gender differences in processing information for making self-assessments of health. Psychosomatic Medicine, 62(3), 354-64. 
Bergqvist, K., Yngwe, M. A., \& Lundberg, O. (2013). Understanding the role of welfare state characteristics for health and inequalities-An analytical review. BMC Public Health. https://doi. org/10.1186/1471-2458-13-1234.

Bonoli, G. (2007). Time matters: post industrialization, new social risks, and welfare state adaptation in advanced industrial democracies. Comparative Political Studies, 40(5), 495-520. https://doi. org/10.1177/0010414005285755.

Borders, T. F., Rohrer, J. E., \& Cardarelli, K. M. (2006). Gender-specific disparities in obesity. Journal of Community Health, 31(1), 57-68. https://doi.org/10.1007/s10900-005-8189-8.

Borrell, C., et al. (2014). Influence of macrosocial policies on women's health and gender inequalities in Health. Epidemiologic Reviews, 36(1), 31-48. https://doi.org/10.1093/epirev/mxt002.

Brennenstuhl, S., Quesnel-Vallée, A., \& McDonough, P. (2012). Welfare regimes, population health and health inequalities: A research synthesis. Journal of Epidemiology and Community Health, 66(5), 397409. https://doi.org/10.1136/jech-2011-200277.

Börsch-Supan, A., et al. (2013). Data resource profile: The survey of health, ageing and retirement in Europe (share). International Journal of Epidemiology, 42(4), 992-1001. https://doi.org/10.1093/ije/dyt088.

Börsch-Supan, A. (2017). Survey of health, ageing and retirement in Europe (SHARE) Wave 6. Release version: 6.0.0. SHARE-ERIC. Data set. https://doi.org/10.6103/SHARE.w6.600.

Carlson, P. (1998). Self-perceived health in East and West Europe: Another European health divide. Social Science and Medicine, 46(10), 1355-1366. https://doi.org/10.1016/S0277-9536(97)10093-4.

Carmel, S. (2019). Health and well-being in late life: Gender differences worldwide. Frontiers in Medicine. https://doi.org/10.3389/fmed.2019.00218.

Daly, M., \& Lewis, J. (2000). The concept of social care and the analysis of contemporary welfare states. The British Journal of Sociology, 51(2), 281-298. https://doi.org/10.1111/j.1468-4446.2000.00281.x.

Dalstra, J. A., Kunst, A. E., \& Mackenbach, J. P. (2006). EU Working Group on Socioeconomic Inequalities in Health. A comparative appraisal of the relationship of education, income and housing tenure with less than good health among the elderly in Europe. Social Science \& Medicine, 62(8), 2046-2060. https://doi.org/10.1016/j.socscimed.2005.09.001.

Deacon, B. (2000). Eastern European welfare states: The impact of the politics of globalization. Journal of European Social Policy, 10(2), 146-161. https://doi.org/10.1177/a012487.

Deaton, A. (2008). Income, health, and well-being around the world: Evidence from the Gallup World Poll. Journal of Economic Perspectives. https://doi.org/10.1257/jep.22.2.53.

Desesquelles, A. F., Egidi, V., \& Salvatore, M. A. (2009). Why do Italian people rate their health worse than French people do? An exploration of cross-country differentials of self-rated health. Social Science and Medicine, 68(6), 1124-1128. https://doi.org/10.1016/J.SOCSCIMED.2008.12.037.

Eikemo, T. A., Bambra, C., Joyce, K., \& Dahl, E. (2008c). Welfare state regimes and income-related health inequalities: A comparison of 23 European countries. European Journal of Public Health, 18(6), 593599. https://doi.org/10.1093/eurpub/ckn092.

Eikemo, T. A., Bambra, C., Judge, K., \& Ringdal, K. (2008b). Welfare state regimes and differences in selfperceived health in Europe: A multilevel analysis. Social Science and Medicine, 66(11), 2281-2295. https://doi.org/10.1016/J.SOCSCIMED.2008.01.022.

Eikemo, T., Huisman, M., Bambra, C., \& Kunst, A. E. (2008a). Health inequalities according to educational level in different welfare regimes: A comparison of 23 European countries. Sociology of Health and Illness, 30(4), 565-582. https://doi.org/10.1111/j.1467-9566.2007.01073.x.

Esser, I., \& Palme, J. (2010). Do public pensions matter for health and wellbeing among retired persons? Basic and income security pensions across 13 Western European countries. International Journal of Social Welfare. https://doi.org/10.1111/j.1468-2397.2010.00737.x.

Feld, S., et al. (2006). Expansion of elderly couples IADL caregiver networks beyond the marital dyad. The International Journal of Aging and Human Development, 63(2), 95-113. https://doi.org/10.2190/ CW8G-PB6B-NCGH-HT1M.

Ferrera, M. (1996). The southern model of welfare in social Europe. Journal of European Social Policy, 6(1), 17-37. https://doi.org/10.1177/095892879600600102.

Garcia-Prieto, C., \& Gómez-Costilla, P. (2017). Gender wage gap and education: A stochastic frontier approach. International Journal of Manpower. https://doi.org/10.1108/IJM-11-2015-0186.

García Villar, J., \& Quintana-Domeque, C. (2009). Income and body mass index in Europe. Economics and Human Biology, 7(1), 73-83. https://doi.org/10.1016/j.ehb.2009.01.006.

Gelman, A., \& Hill, J. (2007). Data analysis using regression and multilevel/hierarchical models. Cambridge: Cambridge University Press.

Guarnizo-Herreño, C. C., et al. (2017). Do welfare regimes matter for oral health? A multilevel analysis of European countries. Health and Place, 46, 65-72. https://doi.org/10.1016/j.healthplace.2017.05.004. 
Hansen, T., Slagsvold, B., \& Veenstra, M. (2017). Educational inequalities in late-life depression across Europe: Results from the generations and gender survey. European Journal of Ageing, 14(4), 407-418. https://doi.org/10.1007/s10433-017-0421-8.

Hox, J. J. (2010). Multilevel analysis techniques and applications. London: Routledge.

$\mathrm{Hu}$, Y., et al. (2016). Trends in socioeconomic inequalities in self-assessed health in 17 European countries between 1990 and 2010. Journal of Epidemiology and Community Health, 70(7), 644-652. https://doi. org/10.1136/jech-2015-206780.

Huisman, M., Kunst, A. E., \& Mackenbach, J. P. (2003). Socioeconomic inequalities in morbidity among the elderly; a European overview. Social Science and Medicine, 57(5), 861-73.

Högberg, B., et al. (2017). Ageing, health inequalities and the welfare state: A multilevel analysis. Journal of European Social Policy, 28(4), 311-325. https://doi.org/10.1177/0958928717739234.

Högberg, B. (2018). Gender and health among older people: What is the role of social policies? International Journal of Social Welfare, 27(3), 236-247. https://doi.org/10.1111/ijsw.12309.

Jeffery, R. W., et al. (1991). Socioeconomic status differences in health behaviors related to obesity: The healthy worker project. International Journal of Obesity, 15(10), 689-696.

Jürges, H. (2007). True health versus response styles: exploring cross-country differences in self-reported health. Health Economics, 16(2), 163-178. https://doi.org/10.1002/hec.1134.

Jürges, H. (2010). Health inequalities by education, income and wealth: A comparison of 11 European countries and the US. Applied Economics Letters, 17(1), 87-91. https://doi.org/10.1080/1350485070 1719835 .

Kunst, A. E., et al. (2005). Trends in socioeconomic inequalities in self-assessed health in 10 European countries. International Journal of Epidemiology, 34(2), 295-305. https://doi.org/10.1093/ije/dyh342.

Lahelma, E., et al. (2002). Multiple roles and health among British and finnish women: The influence of socioeconomic circumstances. Social Science and Medicine, 54(5), 727-740. https://doi.org/10.1016/ S0277-9536(01)00105-8.

Lee, Y. (2000). The predictive value of self assessed general, physical, and mental health on functional decline and mortality in older adults. Journal of Epidemiology and Community Health, 54(2), 123-9. https://doi.org/10.1136/JECH.54.2.123.

Leopold, L., \& Engelhartdt, H. (2013). Education and physical health trajectories in old age. Evidence from the survey of health, ageing and retirement in Europe (SHARE). International Journal of Public Health, 58(1), 23-31. https://doi.org/10.1007/s00038-012-0399-0.

Macintyre, S., Hunt, K., \& Sweeting, H. (1996). Gender differences in health: Are things really as simple as they seem? Social Science and Medicine, 42(4), 617-624. https://doi.org/10.1016/02779536(95)00335-5.

Mackenbach, J. P., et al. (1997). Socioeconomic inequalities in morbidity and mortality in western Europe. Lancet, 349, 1655-1659. https://doi.org/10.1016/S0140-6736(96)07226-1.

Mackenbach, J. P., et al. (2008). Socioeconomic Inequalities in Health in 22 European Countries. New England Journal of Medicine, 358(23), 2468-2481. https://doi.org/10.1056/NEJMsa0707519.

Mackenbach, J. P. (2012). The persistence of health inequalities in modern welfare states: The explanation of a paradox. Social Science and Medicine, 75(4), 761-769. https://doi.org/10.1016/j.socsc imed.2012.02.031.

Manderbacka, K., Lahelma, E., \& Martikainen, P. (1998). Examining the continuity of self-rated health, Great Britain. International Journal of Epidemiology, 27, 208-213.

Maskileyson, D. (2014). Healthcare system and the wealth-health gradient: A comparative study of older populations in six countries. Social Science and Medicine, 119, 18-26. https://doi.org/10.1016/J. SOCSCIMED.2014.08.013.

McCartney, G., et al. (2011). Contribution of smoking-related and alcohol-related deaths to the gender gap in mortality: Evidence from 30 European countries. Tobacco Control, 20(2), 166-168. https://doi. org/10.1136/tc.2010.037929.

Mossey, J. M., \& Shapiro, E. (1982). Self-rated health: A predictor of mortality among the elderly. American Journal of Public Health, 72(8), 800-808. https://doi.org/10.2105/AJPH.72.8.800.

Noël-Miller, C. M. (2011). Partner caregiving in older cohabiting couples. The Journals of Gerontology. Series B, Psychological Sciences and Social Sciences, 66(3), 341-53. https://doi.org/10.1093/geronb/ gbr027.

Obrizan, M. (2018). Quantifying the gap in self-rated health for transition countries over 1989-2014. Comparative Economic Studies, 60(3), 388-409. https://doi.org/10.1057/s41294-018-0067-3.

Read, S., Grundy, E., \& Foverskov, E. (2015). Aging and mental health socio-economic position and subjective health and well-being among older people in Europe: a systematic narrative review. Aging and Mental Health. https://doi.org/10.1080/13607863.2015.1023766. 
Rueda, S., Artazcoz, L., \& Navarro, V. (2008). 'Health inequalities among the elderly in western Europe. Journal of Epidemiology and Community Health, 62(6), 492-8. https://doi.org/10.1136/ jech.2006.059279.

Serrano-Alarcón, M., \& Perelman, J. (2017). Ageing under unequal circumstances: a cross-sectional analysis of the gender and socioeconomic patterning of functional limitations among the Southern European elderly. International Journal for Equity in Health, 16(1), 175. https://doi.org/10.1186/s1293 9-017-0673-0.

Snijders, Tom A.B., Bosker, R. J. (2012). Multilevel Analysis: An Introduction to basic and avanced multilevel modeling. Second edi. SAGE PublicationsSage: London.

Speake, D. L., Cowart, M. E., \& Pellet, K. (1989). Health perceptions and lifestyles of the elderly. Research in Nursing and Health, 12(2), 93-100.

Tepe, M., \& Vanhuysse, P. (2010). Elderly bias, new social risks and social spending: Change and timing in eight programmes across four worlds of welfare, 1980-2003. Journal of European Social Policy, 20(3), 217-234. https://doi.org/10.1177/0958928710364436.

Thorslund, M., \& Lundberg, O. (1994). Health and Inequalities among the oldest old. Journal of Aging and Health, 6(1), 51-69. https://doi.org/10.1177/089826439400600104.

Uccheddu, D., et al. (2019). Gender and socioeconomic inequalities in health at older ages across different european welfare clusters: Evidence from SHARE data, 2004-2015. European Sociological Review, 35(3), 346-362. https://doi.org/10.1093/esr/jcz007.

Verropoulou, G. (2012). Determinants of change in self-rated health among older adults in Europe: A longitudinal perspective based on SHARE data. European Journal of Ageing, 9(4), 305-318. https://doi. org/10.1007/s10433-012-0238-4.

Zajacova, A., Huzurbazar, S., \& Todd, M. (2017). Gender and the structure of self-rated health across the adult life span. Social Science and Medicine, 187, 58-66. https://doi.org/10.1016/j.socsc imed.2017.06.019.

Publisher's Note Springer Nature remains neutral with regard to jurisdictional claims in published maps and institutional affiliations. 